\title{
Latrine utilization and its associated factors among Rural Communities of North Achefer District, Amhara Region, Northwest Ethiopia
}

Ayichew Kishiru

Amhara National Regional Health Bureau

Muluken Azage

Bahir Dar University

Taye Abuhay Zewale ( $\nabla$ tabu0918@gmail.com )

Bahir Dar University https://orcid.org/0000-0002-5356-6214

Kassawmar Angaw Bogale

Bahir Dar University

\section{Research note}

Keywords: Latrine utilization, Hand washing facilities, Hygiene, Sanitation, Amhara Region, Ethiopia

Posted Date: July 16th, 2019

DOI: https://doi.org/10.21203/rs.2.11452/v1

License: () (1) This work is licensed under a Creative Commons Attribution 4.0 International License. Read Full License 


\section{Abstract}

Abstract Objective: In Ethiopia, there has been progress on construction of latrine facilities in all parts of the country through health extension program since 2003. However, there were limited evidence whether the household are using properly or not. Therefore, the aims of this study were to decide level of latrine use and to explore the reasons for latrine use in rural community of North Achefer District, Ethiopia. Result: The proportion of latrine utilization was $44.5 \%$ (95\% Cl: $441 \%, 48 \%)$ among rural communities. Presence of student in household (AOR=4.3, 95\% Cl: 2.25, 8.26), father's able to read and write ( $\mathrm{AOR}=1.5,95 \% \mathrm{Cl}$ : 1.03 , 2.2), duration of latrine ( $\mathrm{AOR}=3.04,95 \% \mathrm{Cl}: 1.88,4.9)$, latrine need maintenance ( $\mathrm{AOR}=0.5,95 \% \mathrm{Cl}: 0.36,0.75)$, short distance of latrine (AOR=0.32, 95\% $\mathrm{Cl}$ : 0.19 , $0.55)$, self-initiation of latrine use $(A O R=0.22,95 \% \mathrm{Cl}: 0.1,0.46)$ and peer pressure for latrine use $(A O R=2.07,95 \% \mathrm{Cl}: 1.04,4.13)$ were factors associated with increased latrine use. Poor quality of latrines, methods of mobilizing community, infrequent supervision and follow up, poor commitment of health extension workers, inadequate knowledge and unfavorable attitudes \& motivations of latrine uses were challenges to use latrine. Key words: Latrine utilization, Hand washing facilities, Hygiene, Sanitation, Amhara Region, Ethiopia

\section{Background}

Sanitation is the provision of facilities and services for the safe disposal of human excreta[1]. Globally around 2.3 billion people still do not have access to sanitation[2]. Inadequate sanitation causes morbidity and mortality[3], and transmit infectious diseases[2]. Sanitation is prevents diarrhea, active trachoma, soil-transmitted helminth infections, and schistosomiasis [4].

According to Ethiopian DHS 2016, improved sanitation coverage was very low[5]. Plenty of studies in the country showed that the available improved sanitations are not being used properly [6-9]. Latrine utilization in the country was found $50 \%[10]$ with the highest level (67.4\%) in Southern Nations, Nationality and People of Regional State followed by Amhara (50\%)[11]. Studies in Amhara Region revealed that the proportion of latrine utilization was range from $52 \%$ to $61 \%[6-8]$. Different factors such as economic status of the household[7, 8,10$]$, latrines quality and placement of latrine facilities[6, 7,12$]$, were identified determinants to use latrine.

The government of Ethiopia and NGOs have been working together to achieve the goal of Second National Health Sector Transformation Plan to have $82 \%$ latrine coverage, to improve sanitation and hygiene across the country by 2019[13]. However, the transformation plan gives stress to the coverage not for utilization which is the main determinant for communicable diseases and malnutrition[4, 8]. In the study area, there is high coverage of latrine (98\%) but sanitation related diseases still remains high $[14,15]$. There is evidence gap on sanitation implementation and type of sanitation interventions which are being reflected by proxy indicators such as latrine utilization and reduction of diarrhea[4]. Combining qualitative and quantitative research approaches enables researchers to investigate complex health-related topics[16] and to examine contextual features of an experience in relation to other influences such as culture, gender, or wellbeing of people or groups experiencing the phenomenon[17]. Therefore, the objectives of this study were to know level of latrine utilization and its associated factors among rural communities of North Achefer District, Amhara Region, Northwest Ethiopia.

\section{Methods}

\section{Study design, area and period}

A community based cross-sectional supplemented with qualitative study was conducted from March to April, 2018 in the North Achefer District. Based on projected population of the 2007 national census[18], estimated population of the district is 251,873 in 2018 . The district has 24 rural and 3 urban Kebeles with a total of 58,575 households [19].

\section{Sample size determination and sampling procedure}

Sample size was calculated using a single population proportion formula designated as

$$
\mathrm{n}=\frac{\left(Z_{\alpha / 2}\right)^{2} p(1-p)}{d^{2}}
$$

by taking proportion of latrine utilization 50\%[7], marginal error (5\%), 95\% confidence level, design effect of 2 and $10 \%$ non-response rate. The total sample size was 843 . This study used multistage sampling technique. First, the district stratified in to two strata based on their climatic zones, as tropical zone (18 Kebeles) and subtropical zone (6 Kebeles). Of which, six tropical and two subtropical Kebeles were randomly selected. Then participants were selected randomly after proportional allocation to each kebele

Focus group discussants were head of district health office, head of catchment Health Center, Health extension focal person, health Extension worker, school directors, students, model female health development army leaders and selected household head. Each FDG was contains 8 participants and a total of 4 FDG was conducted in the district.

\section{Data collection and quality control}


Data were collected using pretested semi-structured questionnaire, observational check list and focus group discussion guide. The questionnaire was first prepared in English and translated into local language (Amharic version) and finally back translated into English to ensure consistency of questions.

One day training was given for data collectors and supervisors. During the discussion, data was collected using note taking and a tape recorder and transcribe by first author and moderators.

\section{Data management and analysis}

Data were entered using Epi info version 7 and export into SPSS version 23 for analysis. Descriptive statistics like frequency tables, figures, percentages and texts were performed. Variable which have $\mathrm{p}$-value $<0.25$ in binary logistic regression analysis was included in the multi-variable analysis. $95 \%$ confidence interval and $p$-value $<0.05$ was used to identify significant variables.

\section{Qualitative Data analysis}

Before transcribing the data repeated listening of the tap recorded data was done to capture the information and written note line by line was done to transcribe data from Amharic to English. Responses arranged in general categories using discussion guide and was analyzed manually using a content thematic approach.

\section{Results}

\section{Socio-Demographic characteristics of respondent}

A total of 810 households were included in the study with a response rate of $96 \%$. The mean ( \pm SD) age of respondents was 46.3 (12.5) years. Most, $660(81.5 \%)$ study respondents reside in sub-tropical. About $215(28 \%)$ fathers and $86(11 \%)$ mothers were literate. Among the households, $695(85.8 \%)$ had children attending at primary or secondary school (Table 1).

\section{Sanitation Facilities}

Of the total households, 771(95.3\%) had functional latrines and 739(91\%), and five hundred forty-nine (67.7\%) required maintenance. Above half household's used grass and wood to superstructure of the latrine facilities (Table 2).

\section{Behavioral factors}

Over all latrine utilization in the study area was $44.5 \%$. Above half $526(65 \%)$ respondents explained open defecation causes diarrheal disease and $78 \%$ of the respondents were satisfied with the latrine utilization (see additional file1). The main reasons to construct and utilize latrines was because of getting advice from health extension workers about its benefit (see additional file2).

\section{Predictors of latrine utilization}

In binary logistic regression analysis, presence of school aged children in the households 4 times more likely to use latrine compared to those who don't have $(\mathrm{AOR}=4.3,95 \% \mathrm{Cl}: 2.25,8.26)$. Households having fathers who can read and write were about 1.5 times more likely utilized its counterpart (AOR=1.5, 95\% $\mathrm{Cl}$ : $1.03,2.2)$. Households owning latrine $>=2$ years were 3 times more likely utilize it than $<2$ years $(\mathrm{AOR}=3.0,95 \% \mathrm{Cl}: 1.88,4.92)$. Households that had latrine $>10$ meters away from home were $68 \%$ less likely to utilize latrine than $<6$ meters away ( $A O R=0.32,95 \% \mathrm{Cl}: 0.19,0.55$ ). Household that had latrines which need maintenance were $50 \%$ less likely to utilize than which don't need ( $\mathrm{OOR}=0.5,(95 \% \mathrm{Cl}: 0.36,0.75)$. Those households who learn the benefit of latrine from peer group were 2 times more consistently utilize it than those enforced by other bodies (AOR=2.11, 95\% $\mathrm{Cl}: 1.05,4.22$ ). The extent of latrine utilization $77 \%$ less likely in the households who construct and use by themselves than households advised by health extension workers ( $\mathrm{AOR}=0.23,95 \% \mathrm{Cl}: 0.11,0.502)($ Table 3$)$.

Qualitative results: Most of the discussants explained that the presence of barriers and negligence on community and health sectors for the consistent latrine utilization. Lack of awareness, the poor quality of constructed latrines, absence of detail understanding on importance of latrine utilization, infrequent supervision and follow up by concerned bodies, shortage of necessary materials for latrine construction, latrines constructed with enforcement without communities will.

\section{Poor quality of latrines (Them 1)}

Discussants raised that majority of constructed latrines had a quality problem.

35 years' health personnel explain that "most of the communities had substandard latrine facilities which needs frequent maintenance and majority served only for dry seasons because of the material they constructed.."

\section{Poor methods of community mobilization (Them2)}

The discussants explain the presence of poor method of community mobilization to construct and use latrine facilities. 
One FGD participants indicates that, "most of latrines constructed with campaign with fear of punishment without teaching the importance of utilizing latrine"

\section{Lack of frequent Supervision and follow up (Them 3)}

From district health office to community level, problems were not solved and no supportive supervision and follow up concerning latrine utilization.

Male FGD participant explained that, "the practice of communities of latrine utilization is different. Some of them practice what is taught by health extension workers. Another did what they understand when they are learning, this categories need follow up. The rest group had poor attitude and do not respond what the health providers saying and the health development army also."

\section{Poor knowledge and attitudes on latrine use (Them 4)}

The majority of FGD participants reported that, "generally latrine utilization was high among those who know latrines as diarrheal disease prevention compared. For example, majority believed that: someone is at risk of getting diarrhea if neighbor practiced open defecation."

\section{Discussion}

This study found that the proportion of latrine utilization among the study area was 44.5\%. This finding is lower than the Awoble District[7], Dembia district[6] and but higher than the study in southeastern Ethiopia[12] and southern Ethiopia[20], in northern Ethiopia Hawzien district[9]. It also less than a study conducted in Eastern Nepal[21] and 2017 JMP report[2]. This difference might be the study period variation (2013 vs 2018) and study area socio demographic and economic status difference.

In this study only few households had hand washing facilities near the latrines. This is higher than the finding from EDHS 2016 report of rural areas [5], rural Tanzania[22] and Kenya[23]. This could be due to scarcity of water, lack of awareness about the importance of hand washing.

Though many knew the benefit of latrine utilization, significant number of them use latrine because it is convenient particularly for females as compared with open defecation. This finding is similar with the result of South Ethiopia, but higher than Northwest Ethiopia[20, 24]. This might be because of lack of awareness.

On the other hand, households who had primary/secondary students more utilize latrine than who didn't. This finding is consistent with the study conducted in Awobel district, Southeast Ethiopia and Eastern Nepal [12, 21,25]. This might be due to school age children were more exposed to hygiene related information in the school. Literate husband household heads more utilize latrine than the illiterate. This finding is inconsistent with the study conducted in the North Ethiopia[9]. This difference could be attributed to the difference in the knowledge and awareness levels of the communities.

Long time of owning latrine encourages latrine utilization. This finding is similar with the study conducted in the gulomekeda district, Northern Ethiopia and Kenya $[26,27]$. This could be associated on focus group discussion if the household members visited frequently and supervised by HEWs and teach them the importance of latrine utilization; this would motivate households to use latrines constantly. Households who had latrines which need maintenance $67 \%$ times less likely to utilize latrine. This result is greater than the study conducted in Awobel district[7]. The reason might be, poor quality of latrine facility construction affects proper utilization.

Households constructing latrine far from home $68 \%$ times less likely to utilize latrine than nearest. This could be because of as latrine is far from home it is difficult to use it at night and during illnesses. Similar findings were reported from North Ethiopia, southeast Ethiopia and study around Addis Ababa city a study $[9,12,28]$.

Households constructing and using latrine by peer influence were more utilize it than enforced by other bodies. But perceived reason of self-initiation was $77 \%$ less likely to utilize than being advised by health extension workers. This result is consistent with the study conducted in Hult Ejju Enessie and Chencha district $[8,20]$. This is also explained in national health extension program which implemented for the provision and promotion of model activities, which serve as trigger for public health intervention.

\section{Conclusions}

This study found that the proportion of latrine utilization among the study area was 44.5\%. This finding is lower than the Awoble District[7], Dembia district[6] and but higher than the study in southeastern Ethiopia[12] and southern Ethiopia[20], in northern Ethiopia Hawzien district[9]. It also less than a study conducted in Eastern Nepal[21] and 2017 JMP report[2]. This difference might be the study period variation (2013 vs 2018) and study area socio demographic and economic status difference.

In this study only few households had hand washing facilities near the latrines. This is higher than the finding from EDHS 2016 report of rural areas [5], rural Tanzania[22] and Kenya[23]. This could be due to scarcity of water, lack of awareness about the importance of hand washing.

Though many knew the benefit of latrine utilization, significant number of them use latrine because it is convenient particularly for females as compared with open defecation. This finding is similar with the result of South Ethiopia, but higher than Northwest Ethiopia[20, 24]. This might be because of lack of awareness. 
On the other hand, households who had primary/secondary students more utilize latrine than who didn't. This finding is consistent with the study conducted in Awobel district, Southeast Ethiopia and Eastern Nepal [12,21,25]. This might be due to school age children were more exposed to hygiene related information in the school. Literate husband household heads more utilize latrine than the illiterate. This finding is inconsistent with the study conducted in the North Ethiopia[9]. This difference could be attributed to the difference in the knowledge and awareness levels of the communities.

Long time of owning latrine encourages latrine utilization. This finding is similar with the study conducted in the gulomekeda district, Northern Ethiopia and Kenya $[26,27]$. This could be associated on focus group discussion if the household members visited frequently and supervised by HEWs and teach them the importance of latrine utilization; this would motivate households to use latrines constantly. Households who had latrines which need maintenance $67 \%$ times less likely to utilize latrine. This result is greater than the study conducted in Awobel district[7]. The reason might be, poor quality of latrine facility construction affects proper utilization.

Households constructing latrine far from home $68 \%$ times less likely to utilize latrine than nearest. This could be because of as latrine is far from home it is difficult to use it at night and during illnesses. Similar findings were reported from North Ethiopia, southeast Ethiopia and study around Addis Ababa city a study $[9,12,28]$.

Households constructing and using latrine by peer influence were more utilize it than enforced by other bodies. But perceived reason of self-initiation was $77 \%$ less likely to utilize than being advised by health extension workers. This result is consistent with the study conducted in Hult Ejju Enessie and Chencha district $[8,20]$. This is also explained in national health extension program which implemented for the provision and promotion of model activities, which serve as trigger for public health intervention.

\section{Conclusion}

In the study, latrine utilization was found to be low. Presence of primary or secondary school students in the household, father's level of education, latrine use by peer influence and duration of latrines two or more years were positively associated with latrine utilization. However, Latrine use by self-initiation, latrine needs maintenance and distance of latrine from home greater than 10 meters were factors negatively associated with latrine utilization.

Poor quality of latrines, incorrect methods of mobilization, infrequent supervision and follow up, poor knowledge and attitudes of the community on latrine utilization, poor participation of concerned bodies on motivating the community, poor commitment of health extension workers, absence of strong school health for latrine utilization were mentioned challenges for latrine utilization.

\section{Limitations}

Since the study is cross sectional, the ability to establish cause and effect relationships is impossible. In addition, there may be professional bias.

\section{Abbreviations}

AOR: Adjusted Odds Ratio, CHERG: Child Health Emergency Response Group, Cl: Confidence Interval, EDHS: Ethiopian Demographic Health Survey, FDG: Focus Group Discussion, HMIS: Health Management Information System, HH: Household, HAD: Health Development Army, JMP: Joint Monitoring Programs, OR: Odds Ratio, PHEM: Public Health Emergency Management, WHO: World Health Organization

\section{Declarations}

\section{Ethics approval and consent to participate}

Ethical clearance was obtained from Instructional Review Board (IRB) of Bahir Dar University, college of medicine \& health science with reference number EPB/220/2018. Permission letter was obtained from Amhara public health institute and sent to all concerned authorities at each level. The aim of this study was brief to the respondents. Written consents were collected from households to participate in the study.

\section{Consent for publication}

Not applicable.

\section{Availability of data and materials}

All the data sets used for this study are available from the corresponding author and can be given with a reasonable request.

\section{Competing Interest}

The authors declare that they don't have any conflict of interest in any aspect of the article

\section{Funding}

Not applicable, there was no sources of funding for this study.

\section{Authors' Contributions.}


AK designed the study, collected, analyzed and interpreted the data, and also drafted the manuscript. Dr. MA Participated in conceptualization the study, design, analyses and interpretation of results as well as editing \& critical review the manuscript. TA and KA conceptualization and designed the study, editing

\& critical review the manuscript. All authors read and approved the final manuscript.

\section{Acknowledgments}

We would like to express my gratitude to Ethiopian Federal Ministry of Health and Bahir Dar University, College of Medicine and Health Sciences for giving this chance to conduct this research.

We would also like to extend our appreciation to North Achefer district health office staff members for giving their support. Lastly, data collectors, supervisors, respondents and all individuals and organizations who have participated for the success of this research are greatly appreciated and acknowledged.

\section{References}

1. Organization, W.H., W.U.J.W. Supply, and S.M. Programme, Progress on sanitation and drinking water: 2015 update and MDG assessment. 2015: World Health Organization.

2. Organization, W.H. and UNICEF, Progress on drinking water, sanitation and hygiene: 2017 update and SDG baselines. 2017.

3. Prüss-Ustün, A., et al., Burden of disease from inadequate water, sanitation and hygiene in low-and middle-income settings: a retrospective analysis of data from 145 countries. Tropical Medicine \& International Health, 2014. 19(8): p. 894-905.

4. Freeman, M.C., et al., The impact of sanitation on infectious disease and nutritional status: A systematic review and meta-analysis. International journal of hygiene and environmental health, 2017. 220(6): p. 928-949.

5. Central Statistical Agency - CSA/Ethiopia and ICF, Ethiopia Demographic and Health Sruvey 2016, 2017, CSA and ICF: Addis Ababa, Ethiopia.

6. Yimam, Y.T., K.A. Gelaye, and D.H. Chercos, Latrine utilization and associated factors among people living in rural areas of Denbia district, Northwest Ethiopia, 2013, a cross-sectional study. The Pan African medical journal, 2014. 18.

7. Gedefaw, M., et al., Opportunities, and challenges of latrine utilization among rural communities of Awabel District, Northwest Ethiopia, 2014. Open Journal of Epidemiology, 2015. 5(02): p. 98.

8. Anteneh, A. and A. Kumie, Assessment of the impact of latrine utilization on diarrhoeal diseases in the rural community of Hulet Ejju Enessie Woreda, East Gojjam Zone, Amhara Region. Ethiopian Journal of Health Development, 2010. 24(2).

9. Ashebir, Y., et al., Latrine use among rural households in northern Ethiopia: a case study in Hawzien district, Tigray. International Journal of Environmental Studies, 2013. 70(4): p. 629-636.

10. Organization, W.H., Healthy Villages-A guide for communities and community health workers. Chapter 3. Water. World Health Organization, Geneva, 2003.

11. Leshargie, C.T., et al., Household latrine utilization and its association with educational status of household heads in Ethiopia: a systematic review and meta-analysis. BMC public health, 2018. 18(1): p. 901.

12. Oljira, D., B. T: latrine use and determinant factors in Southwest Ethiopia. Journal of Epidemiology and Public Health Rev, 2016. 1(6).

13. FMOH, The federal Democratic Republic of Ethiopia Ministry of Health. Health Sector Transformation Plan 2015/16-2019/20. Ministry of Health, August 2015.: Addis Ababa, Ethiopia.

14. North Achefer District Health Office health and health related activities annual report 2015/20162016.

15. Carter Center. Trachoma impact survey In Amhara region, Ethiopia 2015 [cited 2018 25/01]; Available from: https://www.cartercenter..org.

16. Halcomb, E.J. and L. Hickman, Mixed methods research. 2015.

17. Matua, G.A. and D.M. Van Der Wal, Differentiating between descriptive and interpretive phenomenological research approaches. Nurse Researcher (2014+), 2015. 22(6): p. 22.

18. CSA, C., The 2007 population and housing census of Ethiopia, 2007, CSA Addis Ababa.

19. Amhara National Regional State Bureau of Finance and Economic Development, Population to size report. Bureau of finance and economic development, Amhara National Regional State (ANRS), 2017.

20. Koyra, H.C., et al., Latrine utilization and associated factors in rural community of Chencha District, Southern Ethiopia: a community based cross sectional study. American J Pub Health Res, 2017. 5(4): p. 98-104.

21. Budhathoki, S.S., et al., Latrine coverage and its utilisation in a rural village of Eastern Nepal: a community-based cross-sectional study. BMC research notes, 2017. 10(1): p. 209.

22. Kamara, J.K., et al., Understanding the challenges of improving sanitation and hygiene outcomes in a community based intervention: a cross-sectional study in rural Tanzania. International journal of environmental research and public health, 2017. 14(6): p. 602.

23. WAITHAKA, R.W., LATRINE USE AND ASSOCIATED FACTORS AMONG RURAL COMMUNITY MEMBERS IN SAMBURU EAST SUB-COUNTY, SAMBURU COUNTY, KENYA, 2015, KENYATTA UNIVERSITY.

24. Godana, W. and B. Mengistie, Exploring Barriers Related to the Use of Latrine and Health Impacts in Rural Kebeles of Dirashe District Southern Ethiopia: Implications for Community Lead Total Sanitations. Health Science Journal, 2017. 11(2): p. 1.

25. Garn, J.V., et al., The impact of sanitation interventions on latrine coverage and latrine use: A systematic review and meta-analysis. International journal of hygiene and environmental health, 2017. 220(2): p. 329-340. 
26. Debesay, N., et al., Latrine Utilization and Associated Factors in the Rural Communities of Gulomekada District, Tigray Region, North Ethiopia, 2013: A Community Based Cross-Sectional Study. . J Community Med Health Educ 2015. 5(338).

27. Racheal, W.W. Latrine use and associated factors among rural community members in Samburu East-sun country, Kenya. 2015 [cited 20/11/2017; Available from:

https://www.google.com/searchource=hp\&ei=PvlbWtGAL5DLkgWpv7Cg\&q=LATRINE+USE+AND+ASSOCIATED+FACTORS+AMONG+RURAL+COMMUNITI COUNTY\%2C+SAMBURU+COUNTYC+KENYA\&oq=LATRINE+USE+AND+ASSOCIATED+FACTORS+AMONG+RURAL+COMMUNITY+MEMBERS+IN+SAMBUR COUNTY\%2C+SAMBURU+COUNTY\%2C+KENYA\&gs_I=psy-ab.12...0.0.0.144.0.0.0.0.0.0.0.0.0.0...0...1c..64.psy-ab..0.0.0....0.xqqBtC7E1aw.

28. Adane, M., et al., Sanitation facilities, hygienic conditions, and prevalence of acute diarrhea among under-five children in slums of Addis Ababa, Ethiopia: Baseline survey of a longitudinal study. PloS one, 2017. 12(8): p. e0182783.

\section{Tables}

Table 1: Socio-demographic and economic characteristics of respondents households among rural communities of North Achefer District, Northwest Ethiopia, 2018

\begin{tabular}{|c|c|c|}
\hline Variables & Frequency & Percent \\
\hline \multicolumn{3}{|l|}{ Household head $n=810$} \\
\hline Male & 729 & 90 \\
\hline Female & 81 & 10 \\
\hline \multicolumn{3}{|l|}{ Age (years) $n=810$} \\
\hline 15- 29 & 47 & 5.8 \\
\hline 30- 44 & 338 & 41.7 \\
\hline$\geq 45$ & 425 & 52.5 \\
\hline \multicolumn{3}{|l|}{ Place of residence $n=810$} \\
\hline Subtropical & 660 & 81.4 \\
\hline Tropical & 150 & 18.6 \\
\hline \multicolumn{3}{|l|}{ Marital status $n=810$} \\
\hline Single & 6 & 1 \\
\hline Married & 746 & 92 \\
\hline Divorced & 25 & 3 \\
\hline Windowed & 33 & 4 \\
\hline \multicolumn{3}{|c|}{ Fathers level of education $n=762$} \\
\hline Unable to read and write & 501 & 67 \\
\hline Able to read and write & 215 & 28 \\
\hline Primary education and above & 46 & 5 \\
\hline \multicolumn{3}{|c|}{ Mothers level of education $n=797$} \\
\hline Unable to read and write & 690 & 86.5 \\
\hline Able to read and write & 86 & 11 \\
\hline Primary education and above & 21 & 2.5 \\
\hline \multicolumn{3}{|l|}{ Occupation of father $n=762$} \\
\hline Farmer & 756 & 99.25 \\
\hline Merchant & 4 & 0.5 \\
\hline Government employee & 2 & 0.25 \\
\hline \multicolumn{3}{|l|}{ Mothers occupation $n=797$} \\
\hline Farmer & 785 & 98.5 \\
\hline Merchant & 9 & 1.1 \\
\hline Government employee & 3 & 0.4 \\
\hline \multicolumn{3}{|c|}{ Monthly income of the $\mathrm{HH}$ (birr) $\mathrm{n}=810$} \\
\hline$<5000$ & 785 & 97.7 \\
\hline$\geq 5000$ & 25 & 2.3 \\
\hline \multicolumn{3}{|l|}{ Family size $n=810$} \\
\hline One person & 26 & 3.2 \\
\hline 2- 4 people & 296 & 36.6 \\
\hline 5-7 people & 415 & 51.2 \\
\hline Above 8 people & 73 & 9 \\
\hline \multicolumn{3}{|c|}{ Presence primary and high school student in the $\mathrm{HH} \mathrm{n}=810$} \\
\hline Yes & 714 & 88 \\
\hline No & 96 & 12 \\
\hline
\end{tabular}

Table 2: Distribution of participants by environmental factors among rural communities of North Achefer District, Northwest Ethiopia, 2018. 


\begin{tabular}{|c|c|c|}
\hline Variables & Frequency & Percent \\
\hline \multicolumn{3}{|c|}{ Functionality of latrine $n=810$} \\
\hline Yes & 771 & 95.3 \\
\hline No & 39 & 4.7 \\
\hline \multicolumn{3}{|l|}{ Type of latrine $n=810$} \\
\hline Traditional pit latrine & 739 & 91 \\
\hline Improved latrine & 71 & 9 \\
\hline \multicolumn{3}{|c|}{ Distance of latrine from home $n=810$} \\
\hline$<6$ meters & 169 & 21 \\
\hline 6- 10 meters & 447 & 55 \\
\hline$>10$ meters & 194 & 24 \\
\hline \multicolumn{3}{|c|}{ Age of latrine (in years ) $\mathrm{n}=\mathbf{8 1 0}$} \\
\hline$<2$ years & 167 & 20.6 \\
\hline$\geq 2$ years & 643 & 79.4 \\
\hline \multicolumn{3}{|c|}{ Latrine need maintenance $n=810$} \\
\hline Yes & 549 & 67.8 \\
\hline No & 261 & 32.2 \\
\hline \multicolumn{3}{|c|}{ Part of latrine need maintenance $n=810$} \\
\hline Super structure(wall) & 258 & 47 \\
\hline Slabs & 84 & 15.4 \\
\hline Roof & 128 & 23.3 \\
\hline Latrine pit & 79 & 1.3 \\
\hline \multicolumn{3}{|c|}{ Availability of hand washing facilities $n=810$} \\
\hline Yes & 110 & 13.6 \\
\hline No & 700 & 86.4 \\
\hline \multicolumn{3}{|c|}{ Availability of water for hand washing $n=110$} \\
\hline Yes & 89 & 81 \\
\hline No & 21 & 19 \\
\hline \multicolumn{3}{|c|}{ Availability of detergent for hand washing $n=110$} \\
\hline Yes & 32 & 29 \\
\hline No & 78 & 71 \\
\hline
\end{tabular}

Table 3: Predictors of latrine utilization among rural communities of North Achefer District, 2018 


\begin{tabular}{|c|c|c|c|c|c|}
\hline \multirow[b]{2}{*}{ Variables } & & \multicolumn{2}{|c|}{ Utilization } & \multirow[t]{2}{*}{ Crude OR(95\% CI) } & \multirow[t]{2}{*}{ AOR(95\%CI) } \\
\hline & & Yes & No & & \\
\hline \multirow[t]{2}{*}{ Residence of the $\mathrm{HH}$} & Subtropical & 317 & 343 & 1.00 & 1.00 \\
\hline & Tropical & 44 & 106 & $0.45(0.31-0.66)$ & $0.83(0.51-1.34)$ \\
\hline \multirow[t]{2}{*}{ Presence of primary or above student in the $\mathrm{HH}$} & Yes & 343 & 371 & $4.00(2.35-6.82)^{* *}$ & $4.3(2.25-8.26)^{* *}$ \\
\hline & No & 18 & 78 & 1.00 & 1.00 \\
\hline \multirow[t]{3}{*}{ Fathers level of education } & Unable to read and write & 197 & 304 & 1.00 & 1.00 \\
\hline & Abel to read and write & 114 & 101 & $1.721 .25-2.39)^{* *}$ & $1.5(1.03-2.2) *$ \\
\hline & Primary education and above & 24 & 22 & $1.78(0.94-3.38)$ & $1.86(0.89-3.87)$ \\
\hline \multirow[t]{2}{*}{ Type of latrine } & Traditional dry pit latrine & 319 & 420 & 1.00 & 1.00 \\
\hline & Improved latrine & 42 & 29 & $1.90(1.16-3.12)^{*}$ & $1.09(0.61-1.95)$ \\
\hline \multirow[t]{2}{*}{ Duration of latrine } & $<2$ years & 35 & 118 & 1.00 & 1.00 \\
\hline & $\geq 2$ years & 326 & 331 & $3.32(2.2-4.98) * *$ & $3.04(1.88-4.9)^{* *}$ \\
\hline \multirow[t]{3}{*}{ Distance of latrine from home } & $<6$ meters & 92 & 77 & 1.00 & 1.00 \\
\hline & 6-10 meters & 219 & 228 & $0.8(0.56-1.14)$ & $0.87(0.51-1.19)$ \\
\hline & More than 10 meters & 49 & 144 & $0.29(0.18-0.45)^{* *}$ & $0.32(0.19-0.55)^{* *}$ \\
\hline \multirow[t]{2}{*}{ Latrine need maintenance } & Yes & 210 & 339 & $0.45(0.33-0.61)$ & $0.5(0.36-0.75)^{* *}$ \\
\hline & No & 151 & 110 & 1.00 & 1.00 \\
\hline \multirow[t]{2}{*}{ Under five children use latrine } & Yes & 95 & 85 & $1.55(1.12-2.14) * *$ & $1.24(0.85-1.81)$ \\
\hline & No & 161 & 223 & 1.00 & 1.00 \\
\hline \multirow[t]{2}{*}{ Availability of hand washing facility } & Yes & 69 & 41 & $2.35(1.55-3.56)^{* *}$ & $1.25(0.76-2.06)$ \\
\hline & No & 292 & 408 & 1.00 & 1.00 \\
\hline \multirow[t]{4}{*}{ Main reasons using latrine } & Advice by health extension worker & 254 & 274 & 1.00 & 1.00 \\
\hline & Self-initiation & 10 & 57 & $0.18(0.09-0.37)$ & $0.22(0.1-0.46)^{* *}$ \\
\hline & Disease prevention & 68 & 96 & $0.76(0.54-1.1)$ & $0.76(0.5-1.14)$ \\
\hline & Peer pressure & 29 & 22 & $1.49(0.82-2.67)$ & $2.07(1.04-4.13) *$ \\
\hline \multirow[t]{3}{*}{ Responsible promote latrine use } & HAD & 63 & 109 & 1.00 & 1.00 \\
\hline & Kebele leader & 64 & 68 & $1.62(1.03-2.58)^{*}$ & $1.30(0.75-2.24)$ \\
\hline & Health extension worker & 234 & 272 & $1.48(1.04-2.12) *$ & $1.28(0.83-1.97)$ \\
\hline
\end{tabular}

$*$ Significant at $\mathrm{p}$ - value $<0.05 * *$ significant at $\mathrm{p}$ - value $<0.001$

\section{Supplementary Files}

This is a list of supplementary files associated with this preprint. Click to download.

- supplement1.docx

- supplement2.docx 